\title{
Bir Yöntem, Yöntembilim ve/veya Bir Sosyoloji Alanı Olarak Görsel Sosyoloji
}

\author{
Reyhan VARLI GÖRK *
}

Özet

Sosyoloji yazını gözden geçirilerek oluşturulan bu makalede, görsel sosyoloji çalışmalarına giriş niteliğinde bir katkı sunulması amaçlanmaktadır. Bu amaca yönelik olarak 'görsel sosyoloji' kavramı bir yöntembilim, yöntem ve/veya ayrı bir sosyoloji alt-alanı olarak tartışılmıştır. Sosyolojinin bir disiplin olarak kendi sınırlarını oluşturmaya başladığı ilk günden itibaren 'görsel sosyoloji', uygulamalı sosyoloji alanında bir yöntem olarak kabul görmektedir. Toplumsal araştırmalarda egemen yöntembilim paradigmaları arasında yorumsamacı-etkileşimci ve realist yöntembilim arasında kurulmuş bir köprüde toplumsalın ifadesi olan görsel verileri çözümlemekte olan 'görsel sosyoloji'nin, yeni bir sosyolojik alt-alan olarak kendini kabul ettirmesi, bir yöntem olarak buluntu görsel verileri çözümlemenin ötesinde yeni görsel veriler üretme potansiyelinde yatmaktadır.

Anahtar Sözcükler: Görsel Sosyoloji, Toplumsal Araştırma Yöntembilimi, Toplumsal Araştırma Yöntemi, Görsel Veri, Görsel Deneme.

\section{Visual Sociology as a Method, Methodology and/or a Field of Sociology}

\section{Abstract}

This paper, which was created by following a thorough review of sociological literature, aims to serve as an introduction to visual sociology studies. To this end, the concept of 'visual sociology' is discussed as a methodology, a method and/or a subfield of sociology. Ever since sociology began creating its own domain as a discipline, 'visual sociology' has been accepted as a method within the wider field of applied sociology. The admission of 'visual sociology', which analyzes visual data as the expression of the social at the juncture of interpretivist-interactionist and realist methodology, as a sociological sub-field among dominant methodology paradigms in social research, would not only aid the analysis of found visual data, but could also potentially create new visual data.

Keywords: Visual Sociology, Social Research Methodology, Social Research Method, Visual Data, Visual Essay. 


\section{Giriş}

1990'lardan itibaren uygulamalı sosyoloji alanında yapılan çalışmaların çoğunda, toplumsal olanın en sözü geçen biçiminin imgeler olduğunun gözlenmesi, 'görsel sosyoloji'ye olan ilginin giderek arttığını doğrulamaktadır. Sosyoloji alanında görsel veri kullanımının giderek yaygınlık kazanması, bu konu üzerine çalışan akademik içerikli dergilerin sayısının giderek artmasından da anlaşılmaktadır. Bunlar arasında Visual Studies (önceki adı Visual Sociology), Visual Anthropology, Visual Anthropology Review ve beşeri bilimler alanında daha geniş bir yelpazeye sahip olan Visual Communication ile the Journal of Visual Culture ilk akla gelenlerdir. Görsel sosyoloji alanında yazılmış kitaplar (Ball ve Smith, 1992; Banks, 2001; Chaplin, 1994; Pauwels, 1996) ve derlemeler de (Papademas, 1993; Grimshaw and Ravetz, 2004; Hamilton, 2007) bu dergiler kadar önemlidir. Ayrıca, Uluslararası Görsel Sosyoloji Derneği (The International Visual Sociology Association); Britanya Görsel Sosyoloji Grubu (British Visual Sociology Group); Uluslararası Sosyoloji Derneği (The International Sociological Association) içinde yer alan Görsel Sosyoloji Tematik Grubu (Visual Sociology Thematic Group); Uluslararası İletişim Derneği (The International Communication Association) içinde yer alan Görsel İletişim Çalışmaları Bölümü (The Visual Communication Studies Division) ve Uluslararası Görsel Okur-Yazarlık Derneği (The International Visual Literacy Association) gibi kuruluşların ve üyelerinin sayılarının artması kayda değer gelişmelerdir (Pauwels, 2010: 546).

Türkiye'deki sosyoloji çalışmaları ve Türkçe sosyoloji yazını gözden geçirildiğinde ise üniversitelerin Fotoğraf, Sinema ve İletişim bölümlerinde ve görsel-işitsel sistemlerle ilgili merkezlerinde ${ }^{1}$ görsel sosyoloji ile ilişkilendirilebilecek olan çalışmalar dikkat çekmektedir. Sosyoloji Bölümlerinde 'Görsel Sosyoloji' adlı derslerin ve tematik çalışmaların yürütülmesi Türkiye'de de konuya olan ilginin arttığını göstermektedir.

Görsel sosyoloji, toplumda geçerli bir bilimsel kavrayışın toplumun doğrudan gözlemlenmesi ve onun görsel dışavurumlarının-insan eylemleri ve maddi kültür ürünleri-çözümlenmesi ve kuramsallaştırılması ile mümkün olabileceği düşüncesi üzerine temellendirilir
(Pauwels, 2010: 546). Harper’a göre (1988: 55), görsel sosyoloji, toplumsal olguları tanımlamak, açıklamak ve incelemek amacıyla araştırma sırasında bulunan veya üretilen fotoğrafların ve diğer imgelerin veri olarak kullanıldığı sosyolojik yaklaşımların toplamıdır. Ancak, Burri'nin de (2012: 46) altını çizdiği gibi sosyolojinin bir alt-alanı [sub-field] olarak 'görsel sosyoloji' tanımı yapabilmek için sosyoloji kuramlarryla ve görsellerle düşünmeyi birbiriyle bağıntılandıracak olan kavramsal çerçeve yetersizdir. Bu sorunsal üzerine odaklanan bu makalenin içeriği, sırasıyla sosyoloji tarihinde görsel kullanımının özetlendiği bölümün ardından toplumsal araştırma yöntembilimi [methodology] ve toplumsal araştırma yöntemi [method] açısından 'görsel sosyoloji' altalanın olabilirliğini tartışan bölümlerle yapılandırılmıştır.

\section{Sosyoloji Tarihinde 'Görsel'}

Sosyoloji ve fotoğrafın Avrupa'da, eşzamanlı olarak aynı yüzyılda ve aynı toplumsal olayların ardından doğdukları bilinmektedir. Fotoğraf da tıpkı sosyoloji gibi sanayi ve burjuva devriminin çocuğudur ve icadından bu güne toplumun çözümlenmesinde bir araç olarak kullanılmıştır. Öncesinde, yalnızca zenginler ve güçlüler resim ya da diğer görsel sanatlar aracılığıyla görsel bir dünyaya sahip olabiliyorken, fotoğraf imgesinin kitlesel üretimi ve dağıtımı ile birlikte görsel dünya herkes için daha erişilebilir olmuştur (Harper, 1988: 55).

On dokuzuncu yüzyılda sanatta realizm akımının etkisiyle fotoğraf, sanatçıların doğal manzaraları; mimari yapıları; toplumsal durumları ve insanları belgelemek için kullandıkları bir araç olarak önem kazanmaya başlamıştır. On altıncı yüzyılda Peter Bruegel'in köylü resimleri ve Victoria döneminin (1837-1901) sonunda İngiltere'de Emerson'un kırsal yaşamı görüntülediği fotoğraflar (Mewhall, 1975), realist sanatın ilk örnekleridir. Emerson, stüdyo koşulları dışında balıkçıları, tekne imalatçılarını ve onların boş zaman etkinliklerini fotoğraflayan ilk kişidir. Eugene Atget ise yirminci yüzyıl başında Paris sokaklarını fotoğraflamıştır (Harper, 1988: 56).

Görsel sosyolojinin belgesel fotoğrafçılıkla birlikte geliştiği söylenegelir. ABD'de belgeselcilik geleneği, yirminci yüzyıla girerken Jacob Riis'in çektiği göçmenler (Riis, 1981) ve Lewis Hine'ın çektiği çocuk işçiler 
fotoğraflarıyla başlar. 1929'daki ekonomik krizin hemen öncesindeki dönemde Amerikan toplumundaki yoksulluk, işçi hakları, etnik gettolarla ilgili skandal haber fotoğrafçılı̆̆ı, Chicago Okulu'nun alan araştırmalarına dayalı sosyolojik çalışmaları ile eşzamanlıdır. Yine de Chicago Okulu üyelerinin çalışmalarında fotoğraf kullanmamaları şaşırtıcıdır.

1896-1916 yılları arasında, American Journal of Sociology dergisinde yayınlanan makalelerin yalnızca otuz bir tanesinde görsel kullanılmıştır (Stasz, 1979). 1920’lere gelindiğinde ise sosyoloji yazınında fotoğraf, neredeyse yoktur (Harper, 1988: 57). 1920-1960 yılları arasinda yapılan sosyolojik araştırmalarda ise görsel veri nadir kullanılmıştır (Harper, 1988: 58). Bu dönemde, Lynd ve Lynd'in $(1929 ; 1937)$ ABD'deki farklı topluluklar, komşuluk ilişsileri, farklı toplumsal sınıfların ev içi mekan kullanımı üzerine birlikte yaptıkları çalışmalardaki sistematik fotoğrafik belge kullanmaları ayrı bir önem taşır.

1960’lı yıllarda sosyoloji disiplini, hem araştırma yöntemleri hem de kuramsal yaklaşımlar açısından pozitivizm gibi egemen yöntembilim paradigmalarını reddeden birçok sosyal bilimciyi kendine çekmiştir. 0 yillarda hem toplumun kendisi hem de sosyoloji disiplini savaş, ırk, sınıf, toplumsal cinsiyet meseleleriyle çalkalanmaktadır. 'Çatışma kuramı' ile açıklanan çalışmalarda fotoğraflar sıklıkla kullanılmıştır. Bunlar arasında Danny Lyon ve diğer fotoğrafçıların fotoğraflarının yayınlandığı The Movement, eşitlik için mücadele eden siyahların belgesel kaydıdır (Hansberry, 1964'den aktaran Harper, 1988: 59). Bu çalışmayı hazırlayan oyun yazarı olan Hansberry gibi, 1960'ları fotoğraflarla belgeleyen fotoğrafçıların neredeyse tamamı sosyolog değildir.

Max Weber'in (1988 [1922]) izinden giden sosyolojinin amacı toplumun kültürel koşullarını ve anlamlarını anlamaktır [verstehen]. Ancak, klasik sosyologlar, görseli mutlaka kapsaması gereken bir analiz olan anlamayı çoğunlukla ihmal etmişlerdir (Burri, 2012: 46). Sosyoloji disiplinin kurucuları ise aynı çağın ürünü olan fotoğrafı çalışmalarında hiç kullanmamışlardır. Başlangııından bugüne sosyologlar, belirli bir toplumsal süreci harfiyen tercüme etmek yerine toplumun soyut imgelerini (sınıf, cemaat, vb. gibi kavramlar) ${ }^{2}$ üretmişlerdir. Simmel dışındaki klasik sosyologların tümü, görsellerden çıkarım [elicitation] yapmaksızın toplumsal düzeni anlamak yönünde kendi analitik çerçevelerini geliştirmişlerdir. Örneğin, Karl Marx, kapitalizmi tüm detaylarıla tanımlarken, Engels'in İngiliz 'işçi sınıfı' tanımlamasından yararlanmıştır. Bu tarihten yirmi-otuz yıl kadar sonra fotoğrafçı Lewis Hine ve Jacob Riis'in ürettiği fotoğraflarda Amerikan işçi sınıfı, tıpkı Engels'in tarif ettiği gibidir (Harper, 1988: 55).

Frankfurt Okulu temsilcileri Horkheimer ve Adorno (2007) kültür endüstrisini ideolojik ve manipüle edilmiş gördükleri için eleştirirken, film ve popüler medyanın görsel boyutunu incelememişlerdir. Frankfurt Okulu ile yakın temasta olan Walter Benjamin (2008) ise görme biçimlerini ele almış olmasına rağmen daha geniş perspektifte görsel temsillerin toplumsal anlamlarını tartışmayı göz ardı etmiştir.

1960'ların ikinci yarısında Fransız sosyolog Pierre Bourdieu (1990 [1965]) fotoğrafın toplumsal çalışmalardaki kullanımları üzerine yoğunlaşmış ve gündelik yaşamda fotoğraf çekmenin 'toplumsalın bir ifadesi' 3 ve aracı olarak yorumlanabileceğini göstermiştir.

Grady'ye göre (2001: 95), imgelerle çalıştığı bilinen ve gerçek anlamda görsel sosyoloji yapmış olan ilk sosyolog Erving Goffman'dır. İmgeler ve toplumsal yapılar arasındaki bağıntıyı incelediği Gender Advertisements adlı çalışmasında Goffman (1979), toplumsal cinsiyet rollerinin görsel olarak nasıl temsil edildiğini ve reklam panolarında nasıl kalıplaştığını açığa çıkarır. Goffman, reklamlarda kullanılan fotoğraflardaki kadınların poz verişlerindeki geleneksel [vernacular] tutumun toplumdaki genel ahlaki tutumların idealleştirilmesine hizmet ettiğini ileri sürmektedir.

Antropolojik araştırmalarda ise fotoğraf kullanımının daha yaygın olduğu görülür. Andre Leroi-Gourhan 1948 yılında ilk etnografik film konferansını düzenlerken, ünlü Fransız yönetmen Jean Rouch'un kendisine sorduğu "Etnografik film diye bir şey var mı gerçekten?" sorusuna "Evet" yanitı vermekle kalmaz; "Bir alt disiplin olarak görsel antropoloji vardır” diye ekler (Rouch, 2003: 79'dan aktaran Doğan 2013: 75). 
"Yazıya alternatif bir görsel dilin örgütlenmesi" (Doğan, 2013: 75) olarak tanımlanan görsel antropolojinin, "film ve videonun antropolojik bilgi aktarımındaki potansiyelinin keşfedilmesiyle ve ardından yeni dijital teknolojiyle çok daha olanaklı olduğu" (Ruby, 2005: 162) söylenebilir. 1896 yılında antropolojiyle ilgilenen fizikçi ve anatomici Felix-Louis Regnault, Senegal'de Wolof kadınının çömlek yapımını, erken Mısır, Yunanistan ve Hindistan tarzıyla karşılaştırarak anlattığı filmi ile ilk “etnografik film” çeken kişidir (Brigard, 2003: 13-16'dan aktaran Doğan 2013: 76). Regnault'un film yapımındaki teorik odağı, kaybolmadan 'fizyolojik' olarak toplulukları kaydetmektir. Görsel antropolojinin ilk yılları hızla yok olan kültürlere ilişkin ne varsa görsel kayıtlarını oluşturma kaygısı taşıyan 'kurtarma antropolojisi' ile sınırlanmıştır (Pauwels, 2010: 547).

\section{Yöntembilim Olarak Görsel Sosyoloji}

Doğa bilimleri ile sosyal bilimler arasındaki en temel farklılık, yönteme ilişkin değil, yöntembilime ilişkindir. Yöntembilim bilginin nasıl keşfedileceğine ve nasıl doğrulanacağına ilişkin olan toplumsal araştırmanın mantığıyla ilgili bir kavramdır. Sosyolojik araştırmalarda, temel olarak pozitivist, yorumsamacı-etkileşimci [interpretivist-interactionist] ve realist yöntembilim izlenmektedir. Ayrıca, düşünümselliği [reflexivity] önemseyen etnometodoloji ve kadının toplumdaki dezavantajlı konumunu değiştirmeyi ilke edinen feminist yöntembilim gibi yeni yaklaşımlar da vardır.

Doğa bilimlerinde egemen olan tümevarımcı [inductive] pozitivizm sosyoloji araştırmalarına yön veren ilk yöntembilimdir. Bu yaklaşım, toplumsal dünyadaki olguların da tıpkı fiziksel dünyadakiler gibi bizim dışımızda keşfedilmeyi bekledikleri, nesneleştirilebilecekleri, nicel göstergelere indirgenebilecekleri ve doğa yasaları gibi toplum yasalarıyla açıklanabilecekleri varsayımına dayanır. Pozitivist sosyologlara göre kişilerin bireysel bilinç ve zihin halleri sosyolojinin kapsamı dışındadır; çünkü bunlar gözlenemez, nicel göstergelere dönüştürülemez.

Öte yandan yorumsamacı-etkileşimci sosyologlar, toplumsal dünyayı araştırırken bireylerin öznel zihin hallerini ve bilinç durumlarını anlamak gerektiğine inanırlar. Emin olabileceğimiz tek fenomenin bilinç olduğunu iddia eden, bilincin sistematik biçimde incelenmesini esas alan fenomenolojiden esinlenirler. Yorumsamacı yöntembilim, toplumsal dünyanın içsel olarak öznel olduğu, özneler arası etkileşimle toplumsal bilginin günbegün değişebileceği varsayımına dayanır. Bu nedenle araştırmanın öznesi (araştırmacı) ile nesnesi (toplum) arasında bir ayrım gözetmeyen Yorumsamacı sosyologlar, topluma ilişkin gözlenebilir olgular hakkında pozitivist sosyologların aksine nedensel açıklamalar yapmaktan kaçınırlar. Pozitivist yöntembilimcilerin nesnellik iddiasına karşılık yorumsamacı yöntembilimciler öznelliği, Weberci anlamayı olanaklı kılan bir tutum olarak tercih ederler.

Gözlenebilir toplumsal olguların ardında yatan gerçekliği anlamayı hedefleyen Realist yöntembilimciler ise hem toplumsal bağıntılara hem de toplumsal eylemlere odaklanırlar. Realist yöntembilim, toplumsal dünyada her şeyin birbiri ile bağıntısı olduğu bu nedenle toplumun bir bütünlük içinde anlaşılabileceği varsayımına dayanır. İnsan bilincinin bir parçası olan değer yargılarının araştırmaya dahil edilmesini reddetmeyen, realist yöntembilimi tercih eden sosyologlar, toplumu oluşturan bireylerin kolektif bir bilinçle eylemeleri sonucu toplumsal yapıyı değiştirebileceklerine inanırlar.

Klasik sosyologların çok azı imgelerle ilgilenmişler ya da kavramın ikincil anlamı üzerinde yoğunlaşarak imgeyi 'bedenin bir ifadesi' olarak ele almışlardır (Burri, 2012: 46). Bu ikinci yaklaşım, modern toplumun erken dönemleri üzerine yazan George Simmel'in çalışmalarında yer alır. Simmel (2009: 221), 'Duyuların Sosyolojisi' başlıklı makalesinde ise insan kardeşlerimizi duyularımız yoluyla algıladığımızı, bu duyu izleniminin gelişiminin ötekine dair bilgi aracı haline geldiğini, duyduklarımızın ya da hissettiklerimizin bizi nesneye ulaştıran köprü olduğunun altını çizer. Simmel (2009: 222), "tam anlamıyla eşsiz bir sosyolojik kazanımı mümkün kılan organ gözdür” diyerek birbirine bakan bireyler arasındaki bağ ve etkileşimi sağlayan 'görme' duyusunu tüm duyu organları arasında yüceltir. "Görme", sadece "konuşmadan önce geldiği” (Berger, 2009) için değil, bilgi ya da hakikatin yorumlanmasını duyulara dayandıran "çağımızın en ayrıcalıklı duyusu” (Debord, 2001: 97) olarak görüldüğü 
için gözmerkezci paradigmanın temelini oluşturur. Simmel, 'Duyular Sosyolojisi' makalesinde 'göz'ü sosyolojik bir araç olarak tanımlar:

Gözün sosyolojik önemi esasen, kendini iki kişi arasındaki bakışın ilk nesnesi olarak sunan 'yüz'ün ifadesine dayalıdır. İnsanlar ilişkilerimizin en pratik yanlarının bile ne ölçüde karşılıklı bilgiye bağımlı olduğunu (hem de sadece dişsal şeylerin bilgisi ya da sadece karşımızdakinin geçici niyetlerine ve ruh haline dair bilgi değil) pek fark etmiyorlar (Simmel, 2009: 223).

Simmel'in 'Duyuların Sosyolojisi'nde görme duyusu ve karşılıklı bakışma eylemi modern kentsel yaşamdaki en önemli toplumsal ilişki olarak görülür. Kavramın içeriğini daha da genişletirsek, karşılıklı bakışmanın fiziksel ifadesi, bilinç ve zihin halinin bir 'görsel temsil'i olarak düşünülebilir. Simmel (2009: 317-329), modern kentlileşmiş bireyin kentsel toplumdaki çok sayıda uyarana karşı kendi duygusal iç dünyasını korumak adına kayıtsızlaştığını [indifferent] ileri sürer. Birbiriyle dirsek teması içinde yaşayan kentlileşmiş bireyin kayıtsız kalabilmek için karşılıklı bakışmaktan kaçınmasının, karşılıklı bilgi alışverişini kesintiye uğratacağı açıktır. Simmel'e göre bütün bu bilgilerin geometrik mekanı 'yüz'dür. Simmel, bir bireyin kendi hayatının önkoşulu olarak beraberinde getirdiği her şeyin simgesi olarak gördüğü 'yüz'ü aşağıdaki gibi tanımlar:

Geçmişinden hayatının dibine düşmüş ve bireyde kalıcı özellikler haline gelmiş şeyler onda [yüzde] depolanır. [...] Yüz bir ifade organı olarak bakıldığında, bütünüyle teorik bir doğaya sahiptir. El, ayak ya da vücudun bütünü gibi eylemez, insanların içsel ya da pratik davranışını asla desteklemez, sadece başkalarına onu anlatır (Simmel, 2009: 223).

1929 ekonomik buhranının ardından ABD'de tarımsal topraklar ve işgücünü belgelemeyi amaçlayan Çiftçi Güvenliği İdaresi (Farm Security Administration) adına Dorothy Lange, 1936 yılında bir dizi fotoğraf çekmiştir. Bu seri içinde yer alan 'Göçmen Anne' adlı fotoğrafı için "insan yüzü evrensel bir dile sahiptir... aynı ifadeler dünyanın her yerinde geçerlidir" diyen Lange, Simmel'in 'yüz' için söylediklerini başka sözlerle ifade etmektedir
(Açık Kapı, 1992'den aktaran Oral, 2006: 22). Yine de yukarıda adı geçen çalışmaların müellifleri olan erken dönem görsel sosyologlar ve görsel antropologların çoğu, toplumla ilgili görsel verinin bir diğer deyişle imgenin nasıl elde edileceğine, nasıl çözümleneceğine dair herhangi bir yöntem-bilimsel bir arayış içinde olmamışlardır. Açıkçası, hemen hepsi görselin görüntüsel (iconic-betimin betimlenen şeyle aşırı 'benzeşmesi') ve belirtisel (indexicalbetimlenen şeyle olan bağlantının 'doğal veya nedensel bağlantı' olarak algılanması) ${ }^{4}$ gücüne kapılıp, hazır buldukları ya da kendi ürettikleri görüntüleri sergilemişler, bu iki kavram arasında uzanan meşakkatli yolu genel hatlarıyla bile hiç tanımlamamışlardır. Görsel sosyologlar ve antropologlar, görsel veri üretme ve oluşturma sürecinde görsel bir dil ve yöntembilim oluşturma pahasına kamera imgesinin 'görüntüsel ve belirtisel' olma yanının önemle üzerinde durma eğilimindedirler (Pauwels, 2010: 547).

Toplumu oluşturan özneler arası etkileşimle kurulan bağların dışında başka yerlerde kurulan sosyolojik bağlar, 'nesnel bir içeriğe sahip olma', bir başka ifadeyle devlet, eğitim, aile, iletişim (dil) gibi yapısal kurumlara dönüşerek “nesnel bir biçim üretme eğilimindedirler” (Simmel, 2009: 222). Bireyler arasında iletilebilir olan tek şey biçim olduğu için Simmel "konuşulan ve işitilen bir sözün bile, gerektiğinde farklı şekilde iletilebilecek nesnel bir anlamı” olduğunu kabul eder; ancak Simmel'e göre:

İnsanları birbirine bağlayan şeyin bir gözün diğerine bakması olduğu o son derece canlı etkileşim herhangi bir nesnel yapıda billurlaşamaz; aralarında yarattığı birlik doğrudan doğruya olay ve işlev içinde askıda kalır. Ve bu bağ öyle güçlü, ve hassastır ki ancak en kısa hat-gözler arasındaki hat-sayesinde ayakta kalır... Kişi başkasını kendi içine aldığı bakışla kendisini açığa vurur, insan özne nesnesini tanımaya çalışırken yaptığı edimle kendisini nesneye teslim eder. İnsan gözle aynı zamanda vermeden alamaz (Simmel, 2009: 222).

Kişinin vermeden alamaması ya da 'kendi içine aldığı bakışla kendisini açı̆̆a vurması’; bakışma esnasında karşıdakinin bedensel ifadesi ve/veya yüz ifadesinin görme duyusu ile algılanması ile edinilen bilgiyi; Weberci anlamda anladığımıza dair 'kanaatimizi’ 5 , yine 
bakışlarımızla karşıdakine açığa vurmasıdır. Bir sosyoloğun araştırma konusu olan özneyi anlamasını mümkün kılan bu özneler arası etkileşim salt bir yöntem değil bir 'empati' meselesidir. Baker'in (2012: 138) Nilüfer Göle'nin bir söyleşisinden aktardığı gibi "empati bir yöntem değil, kendiliğinden oluşan ve arkadaşlığın, sempatinin ve nihai olarak sevginin ana motifidir." Baker (2012: 139), empati kavramını, 'kayıtsızık' ve 'tepkisizlikten' bir şekilde farklı bir psişe durumu olan 'merak' olarak tercüme ettiği Spinozacı 'admirato' terimi ile açıklar. Empati, Platoncu anlamda "sadece varlık aracılığıyla bir 'idea'ya katılma durumudur; empati bir 'idea' model alındığı (Aristoteles'in terminolojisinde 'biçimi edinildiği') esnada, orada ortaya çıkan şeydir” (Baker, 2012: 140). Baker’a göre (2012: 138), empati sözcüğü "bir duygusal hale” göndermede bulunmaktadır, çünkü ona göre bir sosyolog ilişkiye girmeyi kararlaştırdığı sosyal tipleri 'hissedebilmeli', onlardan 'etkilenebilmelidir'.

Kanaatler yerine imgelerle düşünmeyi esas alan ve bu nedenle duyular arasında görme duyusunu ayrıcalıklı gören Ulus Baker'in (2012: 25) önerdiği 'duygular sosyolojisi' araştırmacı öznenin Marx'ın 'Lumpenproleter'i; Simmel'in 'Yoksul'u; Şarlo'nun 'Göçmen'i; Veblen'in 'Tüketici'si; Weber'in 'Protestan'ı; Dostoyovski'nin 'Budala'sı gibi duygusal varlıklar olan 'toplumsal tipleri' hissedebileceklerini savlar. Baker'e (2012: 137) göre "duygular sosyolojisi, hislerin ve sezginin sosyolojisidir... Hisler basın ve televizyon tarafından yönlendirilebilir ama sezgi hiçbir zaman yönlendirilemez."

Susan Sontag, fotoğraf aracılığıyla bilinen bir olayın, o olayın fotoğraflarının hiç görülmemesi durumundan daha gerçek hale geldiğin ileri sürer (Sontag, 1993: 34'den aktaran Oral, 2006: 23). İmge aracılığı ile aktarılan bilgiye karşı duyulan 'merak' [admirato] o gerçekliğin hiç bilinmemesi, bu gerçekliğe kayıtsız [indifferent] kalınması ihtimalini azaltır. Baker (2012: 187-188), Marx'ın en çok dillendirilen "Filozoflar şimdiye kadar dünyayı yorumlamakla yetindiler, ama önemli olan, onu değiştirmektir"6 sözüne göndermede bulunarak 'bilmemezlik'i bir eksiklik olarak görmez, aksine toplumsal gerçekliklere kayıtsız kalmanın önüne geçecek olan 'yeni’yi yeni deneyleri, yeni arzuları uyaran bir kavram olarak, merak ve empati duygusunun esası olarak görür.

Toplumun doğrudan gözlemlenmesi ve onun görsel dışavurumlarının çözümlenmesi ve kuramsallaştırılması olarak tanımlanabilen görsel sosyoloji, araştırma konusunu nesneleştiren pozitivizm ile değil Weberci 'anlama'yı temel alan 'yorumsamacı-etkileşimci yöntembilim'e yakındır. Görsel ifadenin bilinmeyeni bilme arzusu doğuran 'merak' ve 'empati' duygusunu uyandırarak toplumsal gerçekliği değiştirme arzusunu uyarması, görsel sosyolojiyi aynı zamanda realist yöntembilime de yakınlaştırır.

\section{Araştırma Yöntemi Olarak Görsel Sosyoloji}

Sosyolojik Araştırma Yöntemi toplumsal veri toplarken kullanılan teknikler ve araçlardır. Farklı araştırma araçları kullanıyor olmalarına rağmen fen bilimleri ve sosyal bilimler temelde aynı araştırma tekniğini kullanırlar: gözlem. İçerik çözümleme, anket, mülakat, katılımcı gözlem, tarihsel karşılaştırma ve yazın taramasına dayalı kuramsal araştırma başlıca araştırma teknikleridir. Örneğin, 'görsel sosyologlar' sıklıkla araştırma konusunu (gönderge/referent) temsil ettiğini veya içerdiğini kabul ettikleri imgeleri veri olarak toplarlar ve bu imgelerin içeriğini çözümlerler. Bir göstergeler sistemi olan 'dil' ile oluşturulmuş konuşma metinleri; gazete, dergi ve kitaplarındaki yazılı metinler; film, dizi ve tiyatro oyunlarının senaryoları da içerik çözümleme yöntemiyle incelenebilir. Anket ise araştırma konusunu oluşturan araştırma evreninden belli bir örneklemle seçilmiş kişilerin, toplumun belli bir yüzdesini temsil ettiği varsayımıyla kendilerine sorulan sorulara verdikleri yanıtların istatistiki nicel göstergelere indirgenebildiği veri toplama tekniğidir. Yapılandırılmış ya da yapılandırılmamış sorular eşliğinde araştırma konusunu oluşturan bireylerle yapılan görüşmelerin ses kayıtlarından oluşan mülakatlar çoğu kez küçük topluluklarla ilgili araştırmalar söz konusu olduğunda gözlem, bazen de katılımcı-gözlem tekniği ile desteklenir. Gözlem sırasında araştırmacılar çoğu zaman alan notları tutarlar; ses, görüntü ve video kaydı yaparlar. Tarihsel karşılaştırma yönteminde ise araştırmanın amacına göre geçmişte belli zaman aralıklarında toplanan görsel kayıtlar veya demografik veriler güncel verilerle karşılaştırııır.

Grady (2001: 83), imgelerle çalışmanın sosyolojiye 
katkılar sağlayacağına inanır. En başta, günümüz toplumunda kitle iletişimini giderek egemenliği altına alan görsel medya ve iletilerinin içerdikleri bilginin ötesinde bu görsellerin nasıl üretildiklerinin, nasıl kodlandıklarının ve nasıl tüketildiklerinin çalışmaya değer bir konu olduğunu düşünmektedir. İkinci olarak Grady (2001: 84), tıpkı Simmel gibi imgeyi 'bilginin özgün bir biçimi’ olarak kabul eder. Bilgi içeren bu imgenin, bir yandan elle tutulur bir nesnelliği vardır. Siz ne görüyorsanız kameranın size verdiği de odur yani herhangi bir aksilik olmadığı takdirde imge belli bir zaman-mekanda var olan şeyin kamera tarafından yapılan fiziksel kaydıdır. Diğer yandan imge, kaçınılmaz bir biçimde özneldir çünkü her durumda kamerayı taşıyanın ya da onu yönlendirenin belli bir andaki kendi öznel ilgi odağını yansıtır. Bu nedenle imge, çoğu kez görüntüyü deneyimleyen araştırmacı öznenin önemli yanlarını yakalar. ${ }^{7}$ Özet olarak görüntüler, olağanüstü bir nesnellikle karmaşık öznel süreçleri temsil edebilirler. Üçüncü olarak Grady (2001: 84), imgelerle ve/veya imgeler üzerine düşünmenin, yazmanın ve konuşmanın yalnızca daha canlı tartışmalara yol açmakla kalmayacağını daha yalın daha berrak çıkarımlar yapmamıza olanak tanıyacağını düşünür. Örneğin, nicel verileri kullanan sosyologların çoğu bu verileri artarda sıraladıkları tablolar ve çizelgelere dönüştürerek topladıkları malzemeyi daha anlaşılır bir biçimde sunarlar.

Grady’ye göre (2001: 85), imgelerle çalışmanın sosyolojiye sağladığı katkılardan sonuncusu ve belki de en önemlisi-fotoğraf karesi ya da hareketli film biçimindebelgesel üretme potansiyeli taşımasıdır. Bu potansiyel, 'görsel sosyoloji'nin bir alt-alan olarak kendi çerçevesini oluşturması yönünde ayrıca önem taşımaktadır.

\section{Görsel Veri: İmge}

'İmge’yi sosyolojik araştırmanın ana verisi olarak ele alan görsel sosyologların tercihlerinden biri, araştırmacının bulduğu imgeleri (buluntu görsel veri) kullanması, diğeri ise ilk elden gözlem yapan araştırmacının kendi girişimiyle imgeler üretmesidir (üretilen görsel veri) (Pauwels, 2010: 548). Sosyolojik araştırmalardaki mülakatların ses kayıtları veya etnografik araştırmalardaki alan notlarıyla elde edilen verilerin üretilmesi gibi, görsel sosyolojik araştırmalarda da araştırmacının ilgisini yönelttiği konular hakkındaki bilgiyi sabit fotoğraf ya da hareketli film çekimleri ile kayıt altına almaları görsel verileri üretir (Grady, 2001: 89).

Görsel araştırmalarda görsel verinin kaynağının bilinmesi araştırmanın en sağlam ve en temel ayırt edici özelliklerinden biridir. Pauwels (2010: 551), kaynağına göre görsel verileri beş farklı başlık altında gruplandırır: i. İnsan eliyle yapılmış anonim görseller; ii. İnsan eliyle yapılmış kaynağı belli olan görsellerin toplanması (imge koleksiyonu); iii. Başka araştırmacıların kullandığı görsel veriler; iv. Araştırma konusu olan öznenin kendisi tarafından üretilmiş imgeler; v. Araştırmacının kendi girişimiyle ürettiği imgeler.

\section{Buluntu Görsel Veri}

Toplumsal imgeler, insan eliyle üretilmiş görseller (örneğin, reklamlar, haber filmleri, CCTV izleme sistemleri, Web sitesi içerikleri, karikatürler) olarak araştırmacının emek harcamasına gerek kalmadan her zaman her yerde bulunmakta ve her gün yeniden üretilmektedir. Bugün içinde yaşadığımız toplumun gerçek dünyasına, tarihteki toplumların dünyalarına ve kurgusal gerçek olmayan dünyalar hakkında hazır bulunan bu zengin görsel veri havuzu bugünün teknolojisiyle kolayca ulaşılabilir olmuştur. Güncel ve tarihsel malzemeleri bize sunan bu kalabalık görsel yığınının, kendi içinde çeşitlilik gösteren bir doğası vardır. Bu yığının içindeki naif, işe yarar, sıradan, veya oldukça profesyonel türde toplumun çeşitli kesimlerini (ticaret, devlet, eğitim, eğlence, bilim gibi kurumsal yapılar) kapsayan görseller (aile fotoğrafları, reklam fotoğrafları, kurgusal ya da belgesel filmler, çizimler, haritalar, şemalar, vb.) hem kamusal hem de özel dünyalara ulaşma olanağı sunar (Pauwels, 2010: 550).

İmge koleksiyoncuları (image collectors) olan sosyologlar, buluntu malzemeleri kullandıklarında çoğu zaman görsel veri setinin gerçek kaynağına, üretim koşullarına ve temsiliyet özellikleriyle ilgili geçmiş bilgilere ve bağlamsal ayrıntılara yeterince ulaşamayabilirler. Bu durum genellikle Bit Pazarı'ndan ya da sahaflardan edinilmiş (aile albümleri, vs.) insan eliyle üretilmiş ancak müellifi veya sahibi bilinmeyen anonim görseller hatta müellifi veya sahibi bilinen görseller için de geçerlidir. $\mathrm{Bu}$ nedenle araştırmacılar çoğu zaman, görseli temsil edildiği haliyle (visual as presented), çevresindeki öğelerle birlikte 
ele alarak bir bağlama yerleştirebilecek bilgiye ve kültüre sahip olan araştırmanın konusunu oluşturan kişilere fazlasıyla bağımlı kalırlar (Pauwels, 2010: 550).

Görsel sosyoloji çalışan araştırmacılar araştırma konusu olan özneleri, gösterdikleri görseller (resimler, fotoğraflar, insan eliyle yapılmış diğer görsel nesneler) hakkında konuşmaları için teşvik ederler ve bu bilgileri kendi araştırmalarını doğrulamak için kullanırlar. Bazen de araştırma konusu olanözneleri, bellibirkonu hakkında kendi toplumsal yaşamlarına ilişkin kendi imgelerini (örneğin tipik gündelik yaşamları betimleyen) üretmeleri için teşvik ederler. İlk teknik, 'fotoğraf veya filmden tanımlamaçıkarım' (photo elicitation) olarak bilinir ancak bunun yerine 'görselle tanımlama ya da görsellerden çıkarım' kavramını kullanmak belki daha doğru olacaktır çünkü böylece veri, yalnızca fotografik medyumla sınırlanmayacak, çizilerek yapılan görselleri de kapsayacaktır (Pauwels, 2010: 554). İkinci teknikle elde edilen görseller, araştırma konusu olan öznelerin içinde yaşadığı topluluğa dair davranışların araştırmacının müdahalesi olmaksızın kendileri tarafından kaydedilmesiyle elde edilebilir ancak yine de tamamen doğal olmayabilir.

Belirli bir metodolojik yaklaşımla buluntu görsel verilerle gerçekleştirilecek sosyolojik araştırmalarda herhangi bir veri toplama yöntemi üç aşamalı 8 olarak tasarlanır: araştırma evreninin tanımlanması, araştırma evreninden örneklem seçilmesi ve bu örneklemden elde edilen verinin kodlanması (Grady, 2001: 95).

\section{Araştırmacının Girişimiyle üretilen Görsel Veri}

Toplumda hazır bulunan imgelerin toplanmasıyla yapılan sosyolojik araştırmalarda araştırmanın vurgusu, bu görüntülerin oluşmasına aracılık eden 'ikincil derecede' önemli ama belki de bir daha asla ulaşılamayacak olan görsel gerçekliği çözümlemek [decode] üzerinedir. Ancak görsel araştırmaların bir çoğu (görüntülerin üretilmesi de dahil olmak üzere) sosyal bilimcinin araştırmak için seçtiği konuyu kaydetme süreciyle başlar. Görsellerin araştırmacının girişimiyle üretilmesi veri toplama sürecinin daha kontrol edilebilir olmasını, aynı bağlam içinde üretilmiş görsel verilerin toplanmasını sağlar. Bu durum aynı zamanda daha yansıtımsal [reflective] ve düşünümsel [reflexive] bir sosyolojiye olanak tanır.
Görsel veriler, araştırmacının kendisi tarafından üretilmiş sosyolojik araştırmalar arasında toplumsal değişim (Page, 2001), kentsel süreçler (Suchar, 1992), eğitim (Prosser, 2007), kurumsal kültür (Pauwels, 1996), cenaze ve defin törenleri (Chalfen, 2003), toplumsal cinsiyet (Brown, 2001), gençlik kültürü (Wagner, 1999), toplumsal hareketler (David, 2007), ve göç ve etnik kimlik (Gold, 2007) gibi çalışmalarda dikkat çekmektedirler (Pauwels, 2010: 551).

Barthes (1981), duygusal etki yaratan fotoğraflar için 'punctum' (vurucu) rasyonel ileti aktaran fotoğraflar için 'studium' (konu üzerine çalışılmış-özenilmiş) kavramlarını kullanır. Barthes'a göre 'punctum' fotoğraflar insanın bilincini, zihnini delen, yüreğini deşen fotoğraflardır. Bu ayrımı yaparken aslında Barthes görsel sosyoloji yapmaya niyetli olan sosyoloğa fotoğraf çekmenin veri kaydetmekten öte bir şey olduğunu anlatmaktadır. Görsel veri sosyolojik anlamda çok şey iletebilir ama içimizi sızlatmayabilir ya da yüreğimize dokunur, bilincimizi kanatır ancak sosyolojik bilgi iletmeyebilir. Bazı görsel veriler her iki rolü de üstlenebilir. Barthes'ın izinden giderek fenomonolojik bir yaklaşımla görsel sosyoloji yapan sosyologların birçoğu kendi algıları ve deneyimleri çerçevesinde edindikleri bilgileri veri olarak kullanmayı tercih etmişlerdir. Grady, görsel sosyologlar tarafından üretilen ürünleri 'görsel denemeler' [visual essays] olarak adlandırır ve bunları üç farklı gruba ayırır: foto-deneme [photo essay], belgesel video ya da deneme film [essay film] ve görsel verilerin çözümlenmesi (Grady 2001: 112). Grady, belgesel video, ya da giderek yaygınlaşan adıyla 'deneme film'için 'Betty Tells Her Story’ (1972) 9 yi örnek gösterir.

\section{Araştırmanın Göndergesi [Referent], Konusu [Subject], Betimlenen [Depicted] ve Betimleme [Depicting]}

Sosyal bilimlerde görsel araştırmalar genellikle maddi kültür ürünleri ve insan davranışlarını araştırma konusu olarak seçerler; seçilen konunun [subject] görsel olarak temsil edilebilmesi durumunda bu konu betimlenen [depicted] ya da görsel olarak gönderme yapılan atıfta bulunulan bu içerik araştırmanın göndergesi [referent] olarak adlandırılır.

İçerik veya betimlenen her ne ise araştırmanın göndergesi olan ve araştırmacının girişimiyle 
üretilmiş olan görsellerin büyük çoğunluğu bu konuya odaklanılarak üretilmişlerdir. Araştırmacıların büyük bir bölümü imgeleri üretirken bir başka ifadeyle araştırma konularını betimlerken sistematik bir yöntem izlerler. Bunu yaparken de kamera çekimine özgü değişkenlerin (kamera uzaklığı, kamera açısı, kameranın pozisyonu gibi) farklı uygulamalarından kaynaklanan bir tarzı yansıtan dışavurumcu sonuçları ve farklııkları en aza indirmek amacıyla dolaylı ya da doğrudan bir yaklaşımla kamera imgesinin görüntüsel [iconic], taklitçi gücüne bel bağlarlar. Ardından bu görselleri betimlenen dünyaya açılan pencereler olarak kullanırlar. Oldukça 'gerçekçi' olduğu varsayılan bu yaklaşım, her şeyden önce araştırma için gerekli olan içerikle yani betimlenen şeyin kendisiyle ilgileniyorsak oldukça mantıklıdır. Ancak bir araştırmacı, betimlenen içerik (gönderge) ile betim (görsel temsil/ visual representation) arasında kaçınılmaz olarak var olan farklıığın ${ }^{10}$ her zaman farkında olmalıdır (Pauwels, 2010: 557).

Bugün, toplumsal imgelerin birçok türü (aile fotoğrafları, reklam fotoğrafları, posta kartları, haber filmleri, kurgusal sinema ve belgesel filmler, çeşitli resim-fotoğraf arşivleri, haritalar, tablolar, şemalar) toplum bilimleri, kültürel çalışmalar ve davranış bilimleri alanlarında farklı konuları çalışan araştırmacılar tarafından kullanılmaktadır. Bunlar arasında Margolis'in (1994) emek üzerine yaptığı çalışma ile Musello (1979) ve Chalfen'in (1987) aile dinamikleri hakkında yaptığı çalışmalar ilk örnekler arasında yer alırlar. Toplumsal imgeleri araştırmalarının esası olarak ele alan diğer önemli çalışmalar göç (Wright, 2001), ırk ve etnik köken (Grady, 2007), sağlık (Bogdan ve Marshall, 1997), toplumsal cinsiyet ve kimlik (Edge, 1998; Goffman, 1979), ve küreselleşme (Barndt, 1997) hakkında yapılmışlardır (Pauwels, 2010: 551).

Buluntu görsellerle yapılan araştırmaların öncelikli odağı genellikle betimlenen içerikler (modadaki değişimler, mimarlık, sokak sanatları, etkinlikler, aile fotoğraflarındaki kişiler ve onların poz verme biçimleri, reklam fotoğrafları) üzerinedir. Ancak, araştırmacı temsil pratiğinin (kültürel ve teknolojik normative/kurallara bağlı sistemler) sonucu olan betimleme üzerine odaklanarak da faydalı veriler elde edebilir ve böylece zaman içinde belli nesnelerin ve olayların belli eyleyiciler veya kurumlar tarafından nasıl temsil edildiklerini inceleyebilir. Böylesi araştırmalarda araştırmanın odağı betimlenen içerikten betimlemenin tarzını araştırmaya doğru kayar. Örneğin sömürgecilik çalışmalarında araştırmanın odağı betimlenen içerikten daha çok 'öteki'nin [other] nasıl temsil edildiği-sahnelenmiş [staged], seçmeci [selected], basmakalıp [stereotype], uysallaştırılmış [made docile]üzerinedir (Pauwels, 2010: 557).

Burri (2012: 48), tıbbi imgelerin üretildiği merkezlerde yürüttüğü etnografik çalışmasında, görüntüleme pratiğinin nasıl bir görsel mantıkla işlediğini inceler. Bu çalışmasında Burri, 'görsel mantık' olarak adlandırdığı kavramı detaylandırarak imgelerin toplumsal pratikte rol oynayan üç farklı görsel boyutunu tanımlar. Bu boyutlardan ilkini görsel değer, ikinci boyutunu görsel performans üçüncü boyutunu görsel ikna edebilme gücü olarak adlandırır. Burri'nin kavramsallaştırmasıyla imgelerin bu üç boyutu birlikte 'görsel mantığı' oluşturur.

Burri'nin (2012: 48) imgelerin söylem-dışı nitelikleri olarak tanımladığı Görsel Değer görsel bilginin anında [simultaneous] algılanmasını mümkün kılar. Burri, görsel değeri işitme, koku alma, tat alma ve dokunma duyuları ile iletilen tüm diğer göstergelerden farklılaştıran imgelerin 'artı değeri' olarak tanımlar. Görsel değer, toplumsal pratikle inşa edilir; görsel göstergeler olan imgeleri, numerik ya da metinsel olan diğer göstergelerden ayırt eden fenomonolojik bir ölçüt olarak işlev görür. Sanat tarihçiler, Burri'nin görsel değer olarak kavramsallaştırdığı imgeye özgü olan bu niteliğini, imgelerin metinsel ya da numerik göstergelere indirgenemez görüntüsel (iconicbetimin betimlenen şeyle aşırı 'benzeşmesi') farklılığı olarak adlandırırlar (Boehm 1994'den aktaran Burri, 2012: 50). Bununla kastettikleri, bir imgenin metinden daha fazla olmasıdır. Toplumsal pratikte imgelerin görsel değeri, toplumsal eyleyicilerin görsel bilgiyi anında algılamasını sağlayan özelliğidir. Oysa metinsel bilgi içsel olarak ardışıktır. Bu nedenle imgelerin görsel değeri, toplumsal eyleyicilerin bir çırpıda daha büyük miktarda bilgiyi iletmesini ve algılamasını mümkün kılmaktadır (Burri, 2012: 50). 
Burri'nin (2012: 48) bir imgedeki görsel işaretlerin kompozisyonu olarak tanımladığı Görsel Performans, imgenin üretilmesi esnasında alınan özgül estetik kararların sonucu elde edilir. Bu estetik kriterler toplumsal pratiklerle elde edilir ve öğrenilir. Estetik tercihlere ek olarak, herhangi bir imgede düzenlenen göstergeler profesyonel beceri ve sıklıkla yerel toplumun örtük kuralları sonucu oluşur (Burri, 2012: 50).

İletişim sırasında görsel bilginin önemini ve imgenin retorik gücüne karşılık gelen Görsel ikna edebilme gücü, imgelerin estetik değerine bağlıdır-bir imge estetik anlamda ne kadar güzel, ne kadar dikkat çekici ve ne kadar etkileyici ise o kadar ikna edicidir (Burri, 2012: 52). Burri (2012: 53), imgenin görselliğinin en önemli boyutunun ikna edebilme gücü olduğunu düşünür çünkü toplumsal pratikte imgeler aracılığıyla gerçekleşen bilgi iletişimi metinsel iletişimden daha etkilidir.

\section{Sosyolojik Alt-Alan olarak Görsel Sosyoloji}

Geçmişte imgelerle yapılmış sosyolojik çalışmalar daha çok yöntem sorunsalı üzerine odaklanan, imgeyi (gösteren) ve içeriğini (gösterilen) araştırma nesnesi olarak ele alan çalışmalardır. Burri (2012: 54), bu yaklaşımın üç yönünü tartışmaya açar. Burri'ye göre, her şeyden önce yeterli bir sosyoloji yapabilmek için imgeleri yorumlamak ve kullanmak tek başına yeterli olmamalıdır, bunun yerineimgelerin içeriğini açı̆̆a çıkarmak için-imgelerin kültürel anlamları nasıl biçimlendirdiği incelenmelidir. Bu bakış açısı görsel temsillerin kültürel algılamayı nasıl şekillendirdiğini ve görme rejimlerini nasıl değiştirdiğini anlamayı amaçlar.

İkinci olarak, imgelerle yapılan sosyoloji yalnızca anlam içeren yapıları temsil eden biçimleri analiz etmekle yetinmemeli aynı zamanda bu yapıların nasıl oluşturulduğunu araştırmalıdır (Burri (2012: 54). Son olarak Burri (2012: 54), kültürel koşulların ve imgelerin anlamlarının analizinin imgelerin maddiliğini yansıtacağını ileri sürer çünkü imgeler kendiliğinden var olan şeyler değildirler; aksine toplumsal pratikle üretilirler. İmgeler, üretilmeleri, okunmaları (anlamlandırılmaları) ve dağıtımları sürecindeki toplumsal pratikle birer toplumsal gerçekliğe dönüşürler. Görsel çalışmaların büyük bir çoğunluğu betimlenen içeriği incelerler ancak görsel veriyi betimleme aşamasına ilişkin incelemeler, betimlenen içerik hakkında çok önemli bilgileri (örneğin, imgeyi üreten ya da sipariş eden kişiler ve/veya kurumların sahip olduğu normlar ve değerler) açığa çıkarabilir (Pauwels, 2010: 560).

Pauwels'a (2010: 559) göre görsel sosyoloji ‘hukuk sosyolojisi', 'kent sosyolojisi' gibi ayrı bir alan değil, farklı araştırma alanlarını kesen ve bu alanlardaki araştırma süreçlerinin (kavramsallaştırma, veri toplama ve iletişim) bütününü etkileyen bir sosyolojik düşünme ve anlama yöntemidir. Her ne kadar Pauwels (2010: 561), imge üretmeye yönelik gerekli olduğunu düşündüğü teknik bilgiye ek olarak epistemolojik bilginin altını çizmiş olsa da onun 'görsel sosyoloji' tanımı, sosyolojinin tüm alt alanlarında araçsallaştırılabilecek olan bir veri toplama ve çözümleme yöntemi olarak anlaşılmaktadır. Araştırmacı öznenin araştırma konusuna ilişkin bir çıkarımı olan 'bilgi'nin kaynağına ilişkin temel sorular soran epistemoloji, bilen ile bilinen arasındaki ilişkiyi konu edinir. Epistemolojik açıdan bir araştırmacı, duyuların ve bu duyular arasında 'görme'nin araştırma konusu olan toplumsal 'gerçekliğe' dair bilgiye ulaşmak ve bu bilgiyi 'doğrulamak' için en yetkin yöntem olduğuna inanmakla başlayabilir 'görsel sosyoloji' yapmaya. Kendi gördüklerini, hatta göremediklerini kameranın gözüyle kaydederek imgeler üretmesi ise teknik bir becerinin ötesinde kuramsal bilgiyi de gerektirir.

Baker(2002), bilimolaraksosyolojinin birenformasyon ya da 'bilme' türü olmaktan çok, insanlara kendi dünyaları, yaşamları ve amaçları, istekleri ve ihtiyaçları konusunda ne düşündüklerini soran bir araştırma tekniği olarak kendini sınırlandırma tehlikesiyle karşı karşıya kaldığı konusunda bizi uyarmaktadır. Araştırma konusunu daha çok içerecek imgeleri üretmeyi amaçlayan, daha yaratıcı bir sosyoloji olarak önerdiği 'duygular sosyolojisi'ne doğru yolculuğun görsel-işitsel sosyolojiden geçtiğini aşağıdaki sözlerle anlatır:

Derdim sosyal bilimlerde eksik olan bir şeyi, 'belgesel' denen ama bence filmik yaşantıların toplamına yayılması gereken bir uğraşıyla bütünlemek, entegre etmekti. Benim 'film-deney' ve 'film-fikir' dediğim şeylerden başka bir uğraşım yok. Ne belgeselciyim ne 
de video sanatçısı. Sonuçta bir 'görsel-işitsel arşiv' sıkıntısı çeken bir sosyal bilimci diyebilirsiniz bana. Ama diğer sosyal bilimciler gibi videografik kaydın ve arşivin salt bir illüstrasyondan ibaret olamayacağını hissediyorum. Mesela 'yoksulluk' üstüne bir araştırmada çevrede, odanın içinde gezdirilen bir kameranın bir anketin metinsel kayıtlarından çok daha 'bilgi verici', yani 'duygulandırıcı' olabileceğini biliyorum (Baker, 2002b).

Baker'in önerdiği 'duygular sosyolojisi', gözü ve görme duyusunu sosyolojik düşünmenin merkezine alarak, toplumsal gerçekliğin görsel kayd olan fotoğraf ve videonun bilgi-belge üretme potansiyeline işaret eden, bir 'görsel sosyoloji'dir. Vertov'un (2007'den aktaran Baker, 2012: 323) "sine-göz zamanın teleskobu ve mikroskobudur" sözüne kiymet vermekle birlikte Baker (2012: 131-135), kamerayı (Vertov'un kavramı olan sine-gözü) salt bir teknik araç olarak değil, Godard'dan esinlenerek sosyolojik kavrayışı mümkün kılan bir "düşünme cihazı" olarak görür ve sine-gözü aşağıdaki gibi tanımlar:

Sine-göz, şeylerin oluşu içinde, imajların bünyesine yalnızca hareketi değil, zamanı da yerleştirmeyi başarabilir. Böylece bedenlerdeki yoğunluğu ve cisimselliği-olmayan ögeyi yakalayabilir. Kameranın beklenmedik hareketleri ve montaj bizi beşeriolmayan, saf bir zamanı ve değişimlerin hızlarını doğrudan deneyimlemeye yöneltebilir (Baker, 2012: 320).

Ancak, Pauwels (2010: 560), kameranın otomatik olarak araştırma konusu hakkında çok geniş kapsamlı veri toplayacağı beklentisine kapılmanın naif bir yaklaşım olacağı konusunda sosyologları uyarır. Görsel verilerle araştırma yapanlar çalışmalarını çeşitli kuramsal çerçeveler (örneğin göstergebilim, retorik, yapısalcılık, marxizm, psiko-analiz, kültürel çalışmalar, post-kolonyal kuram, feminist kuram) içinde yürütürler.

Bir bilgi araştırma konusunu ne kadar doğru içerirse gerçeğe o kadar yakındır. Ancak araştırma konusunun bütünüyle kavranması mümkün değildir. $\mathrm{Bu}$ nedenle bir bilgi bilimsel olsun olmasın, araştırma konusunu kavraması sınırlı olduğu için her zaman eksiktir. Bilimde daha fazla düşünümsel ve daha yansıtımlı bilgi arayışı göz önüne alındığında, bilginin tamamının aslında 'henüz tamamlanmamış' bir bütüne ulaşmaya çalışan, yarı mamul, eksik ve derinlemesine incelemeci bir öngörü olduğunu kavrarız (bkz. Pauwels 2006b; Rosaldo 1989; Ruby 2000). Görselaraştırmalara (yadabiralanolarakgörselsosyolojiye) baktığımızda ise, daha düşünümsel ve yansıtımlı bir bilgi arayışının araştırmayı kültürlerin karmaşık bir buluşması (araştırmacıların kendi kültürleri, bireysel inanışları, tercihleri, deneyimleri, kişilik özellikleri, kültürel birikimi ile araştırılan kişilerin kültürleri ve sonraki aşamada görsel ürüne bakan izleyicilerin kültürel bakış açısı) olarak gören ve araştırmayı somut bir şekle sokma (imgeler oluşturma) çabası ile karşılaşırız (MacDougall 1975:119'dan aktaran Pauwels, 2010: 565 ).

Görsel sosyoloji araştırmalarının sonucunda elde edilen ürünler farklı somut biçimlerde olabilir: standart akademik makale veya araştırma raporu (yalnızca sözcükler, tablolar ve grafikler), bağımsız filmler, DVD üzerinde veya web ortamına yayınlanmış multi-medya programlar. Bu ürünler arasında, "görsel denemeler" (visual essays) başlı̆ı̆ altındaki foto-deneme ve denemefilm görsel raporlama biçimi olarak diğerlerinden farklılaşırlar (Pauwels, 1993). Akademik yazında tanımı sorunlu bir kavram olan 'deneme-film' hakkında üzerinde uzlaşılan görüşlerin en önemlisi; öznel [subjective], özyansıtımlı [self-reflective], öz-düşünümsel [self-reflexive], eksik ve tartışmaya açı bir bilgiyi içeriyor olmasıdır (Rascaroli, 2008).

\section{Sonuç}

Bu çalışma kapsamında 'görsel sosyoloji' kavramı, yöntem ve yöntembilim açısından incelenmiş, sosyolojik bir altalan olarak tanımlanabilme koşulları tartışılmıştır. Bir disiplin olarak tanımlandığı ilk günden itibaren sosyoloji, temel araştırma yöntemi olarak toplumu gözlemiştir. Bu açıdan bakıldığında 'görsel sosyoloji', her şeyden önce başlı başına bir toplumsal araştırma yöntemidir. Kavram olarak 'görsel sosyoloji', bir yöntembilim değildir. Toplumu doğrudan gözlemleyen, onun görsel dışavurumlarını çözümlemek ve kuramsallaştırmak için imgeleştiren ve bu imgeleri Weberci bir yaklaşımla 'anlama'ya çalışan görsel sosyologların, 'yorumsamacı-etkileşimci yöntembilim’i izledikleri toplumsal gerçeklikleri içeren 
bu imgelerin bilinmeyeni bilme arzusu doğurması sonucu 'merak' ve 'empati' duygusunu uyandırarak toplumsal gerçekliği değiştirme arzusunu uyarmasını amaçlayan görsel sosyologların ise realist yöntembilim'i izledikleri düşünülebilir.

Giriş bölümünde belirtildiği gibi, bu çalışmanın temel amaçlarından biri, 'Görsel Sosyoloji' kavramını sosyolojik bir alt-alan olarak tanımlama koşullarını tartışmaktır. Sosyolojik bir alt-alan olarak 'görsel sosyoloji', sosyolojik araştırmaların konularını oluşturan toplumsal gerçeklikleri (toplumsal yapılar, anlam barındıran kolektif temsiller ve toplumsal eylemler), duyular aracılığıyla hissedip, bu gerçeklikleri imgelerle betimleyerek içerdikleri anlamları görme duyusu başta olmak üzere duyuları aracılığıyla başkalarına da hissettirmeyi esas alan sosyolojik düşünme biçimidir. Böylesi bir sosyolojik düşünme biçimiyle araştırma yapan bir sosyoloğun görsel veri üretmeye başlaması, görsel sosyolojinin bir alt-alan olma potansiyelini açı̆̆a çıkaracaktır.

\section{Notlar}

11993 yılında ODTÜ'de kurulan Görsel İșitsel Sistemler Araştırma ve Uygulama Merkezi'nde (GİSAM) belgesel film, video üretimi, senaryo, fotoğraf gibi konularda atölyeler düzenlenmekte ve projeler yürütülmektedir (https://gisam. metu.edu.tr/gisam-tarihce) (06.08.2015)

2 Deleuze'un (1996: 37-56) felsefeciler için kullandığı "yeni kavramlar üretme" amacına gönderme yapan Ulus Baker (2002; 2012), sosyoloğa 'toplumsal tipler’ yaratma sorumluluğunu yükler. Klasik sosyologların bu konuda verimli olduklarını düşünen Baker'e göre sosyoloji, bu becerisini zaman içinde kaybetmiş ve "kanaatlerin kanaati" haline gelmiştir.

3 “'Pierre Bourdieu: Cezayir'de' başlıklı sergi, fotoğrafçıların fotoğrafın keşfedilmesinden bu yana, sanatçıların ise en azından 1960'lardan beri sanatın kendine özgü bir bilgi biçimi olarak gündeme gelmesiyle yoğun olarak ürettikleri 'görsel antropolojik' verilerden oluşuyor... Bourdieu'nun 1958-1961 yıllarında Cezayir'de gerçekleştirdiği saha araştırmalarının bir uzantısı olan bu fotoğraflar, kentsel ve kırsal alanlarıyla bir ülkeye dair ipuçları edinmek için bire bir. Bourdieu, görmek ve daha yakından görmek için; fotoğraf objektifinden bakmanın başka türlü bir keskin görüş sağladığını bilerek çekmiş bu fotoğrafları... Bu fotoğraflara salt birer görsel veri, birer belgesel kayıt olarak; Bourdieu'nun sanat değil, sosyoloji yaptığını bilerek bakmalıyız" (Antmen, 2007).
4 Değirmenci (2015: 2), imgedeki belirtisellik iddiasının "fotografik yüzeyi 'gerçeğin' bir kalıntısı, izi ya da baskısı olarak görmekten kaynaklandığının" altını çizer. Bu yaklaşıma göre fotoğraf, nesnenin kendisinin izini taşıdı̆̆ için bir yapıntı değil doğal bir olgu olarak tahayyül edilmektedir.

5 "Kanaat bir şeyi ön varsayar: bu bir kanaat ya da yargının terimin klasik anlamıla 'bilimsel bilgi' olmak yerine, evvelce duygulanılmış bir durumu yansıtması anlamında ‘duygudan' başka bir şey değildir” (Baker, 2012: 138).

6 “Çocuk yaşlarındayken kendisi de bir fabrikada uzun saatler çalışmış olan Lewis Wickes Hine, 1911 yılında Ulusal Çocuk Emeği Komitesi'ne fotoğrafçı olarak atanır. Hines'ın toplumsal belgesel fotoğraf tavrının en verimli olduğu bu dönemde, ABD'deki çocuk işçilerin durumu belgelenir ve bu belgesel fotoğraflar belli yaşlardaki çocuk işçileri korumaya yönelik bir çocuk emeği kanunun çıkarılmasında etkili olur" (Oral, 2006: 21).

7 Paul Strand (1971), dünyanın dört bir yanında çektiği köylü portrelerinde, kişisel ifade unsurunu bilinçli bir tercihle kullanmıştır. "Strand'ın portreleri, fotoğrafı çekilen kişilere karşı duyulan yoğun saygı ifadesi taşır, köylüleri zorlu yaşam koşullarına rağmen güçlü, sağlam, dayanıklı ve geleneksel değerleri olan iyi insanlar olarak betimler. Strand bu portrelerle gerçek köylü yaşamını aktarırken kendi bakış açısını, konularını her zaman göz seviyesinde, doğrudan kameraya bakarken çekerek yansıtmış, bu şekilde onları kendi eşiti olarak değerlendirmiştir. Onları savunmasız yakalamak yerine kendilerini en iyi gösterdiğini düşündükleri poz verme olanağını sağlamıştır... Antropolog Frank Cancian'ın (1974) Meksikalı köylü fotoğrafları ise daha çok eski etnografik betimlemeleri anıştıran bir köylü imajı veren farklı kişisel ifade unsurları taşır. Strand'ın köylü portrelerindeki asaletin yerine Cancian'ın köylü portreleri daha az soylu görünürler. Strand'ın fotoğraflarındaki saygı ifadesi yerine bu portreler daha az saygılı bir yakınlıktan ve teklifsiz bir tanışıklıkla çekilmiştir” (Becker, [1974] 2006: 65).

8 Grady (2001: 96), buluntu görsellerin veri olarak kullanıldığı Goffman'ın Gender Advertisements (1979) adlı çalışmasına benzer bir araştırma tasarımı örneği verir: İlk aşamada araştırma evreni olarak 'Magazinler' seçilebilir; ardından genç, kadın, erkek, moda, spor, vb., konu başlıklarından biriyle daraltılabilir. İkinci aşamada, belli bir okuyucu kitlesi için yayınlanan bir ya da birkaç magazin ismi seçilir ve bu magazinin yayınlanmaya başladığı ilk günden son sayısına kadar belli bir zaman aralığındaki sayılar belli bir örneklem oluşturmak için seçilir... İmgeler, içerik çözümlemeye başlamadan önce numaralandırılır. Üçüncü aşamada birer veri olarak çözümlenecek olan görseller belirli kavramlar altında kodlanır. Goffman'ın çalışmasındaki gibi örneğin, "kadınsı dokunuş" (feminine touch) hangi kavramlar altında kodlanabilir? Bu kavramların seçimi araştırmanın amacına ve kuramsal çerçevesine 
uygun olarak belirlenebilir: örneğin, çıplaklık, erotiklik, uysallık, vb. Asıl mesele bu kavramların, bu içeriklerin imgede ne ile gösterildiğini tanımlamaktır. Bir omzun görülmesi mi? Tamamen çıplak olmak mı? Başını eğmek mi? Uzun saçlar mı? Gösterilen ve gösteren arasındaki ilişki, araştırmacının kodlamasıyla kurulur.

9 'Betty Tells Her Story' (1972): Bu filmde, Betty adında bir kadından bir giysiyi alma hikayesini dinleriz. Betty'den aynı hikayeyi yeniden anlatması istenir. Betty bu kez tamamen farklı bir hikaye anlatır. İki hikaye arasındaki tezat, giysi ve giyinme ekseninde Betty'nin kimliği ve dünyadaki yeri hakkında bize çok şey anlatır.

10 Adanır (2015: 1), fotoğrafik imgenin gerçekliğin sadece bazı özelliklerini yansıtabileceğini, zihnin geriye kalan kısmını önceden sahip olduğu bilgiyle ya da ilişkilendirdikleriyle tamamlayacağını ileri sürer. Adanır’a göre (2015: 1), “imge, hiçbir zaman, gerçek ya da gerçekliğin yerini alamaz, olsa olsa yansıtabildiği kadarıyla gerçek ya da gerçekliğin çok küçük bir bütününün imgesi olabilir."

\section{Kaynakça}

Açık Kapı (La Puerta Abierta) (1992). "İspanyol Fotoğraf Belgeseli TV Metni”, çev. Simber Atay, TRT.

Adanır, Oğuz (2015). “Sinematografik İmge ve Gerçeklik”, Uşak Üniversitesi Sosyal Bilimler Dergisi (8): 1-7.

Adorno, Theodor W. (2007). "Kültür Endüstrine Genel Bir Bakış", Kültür Endüstrisi Kültür Yönetimi, çev. Nihat ülner, Mustafa Tüzel, Elçin Gen, İstanbul: İletişim, s. 109-149.

Baker, Ulus (2002). From opinions to images: towards a sociology of affects. Yayınlanmamış Doktora Tezi, Ankara: ODTü, Sosyal Bilimler Enstitüsü.

Baker, Ulus (2012). Kanaatlerden İmajlara Duygular Sosyolojisine Doğru, çev. Harun Abuşoğlu, İstanbul: Birikim.

Ball, Michael S. ve Gregory W. H. Smith (1992). Analyzing Visual Data. Newbury Park, CA: Sage.

Banks, Marcus (2001). Visual Methods in Social Research. London: Sage.

Barndt, Deborah (1997). "Zooming Out/Zooming in: Visualizing Globalization”, Visual Sociology (12): 5-32.

Barthes, Roland (1981) Camera Lucida: Reflections on Photograph. New York: Hill and Wang.

Becker, Howard, S. (1974). "Photography and Sociology”, Studies in the Anthropology of Visual Communication (1): 3-26.
Becker, Howard, S. (2006 [1974]). “Fotoğraf ve Sosyoloji”, çev. Berin Yanıkkaya. Toplum Bilim (19): 45-67.

Benjamin, Walter (2008 [1936]). “Teknik Olarak Kopyalanabildiği Çağda Sanat Yapıtı”. Sanat/Siyaset: Kültür Çağında Sanat ve Kültürel Politika, (der) Ali Artun, İstanbul: İletişim, s: 91129.

Berger, John (2009). Görme Biçimleri. İstanbul: Metis Yayınları.

Boehm G. (ed.) (1994). Was ist ein Bild? München: Wilhelm Fink.

Bogdan, Robert ve Ann Marshall (1997). "Views of the Asylum: Picture Postcard Depictions of Institutions for People With Mental Disorders in the Early $20^{\text {th }}$ Century", Visual Sociology, (12): 4-27.

Bourdieu, Pierre (1990 [1965]). Photography: A Middle-Brow Art. Stanford, CA: Stanford University Press.

Brigard, Emilie, (2003). "The History of Ethnografic Film", Principles of VisualAnthropology, Paul Hockings (ed.), Berlin: Mouten de Gruyter, s.13-43.

Brown, Brian J. (2001). "Doing Drag: A Visual Case Study of Gender Performance and Gay Masculinities", Visual Sociology (16):37-54.

Burke, Caroline ve Ian Grosvenor (2007). "The Progressive Image in the History of Education: Stories of Two Schools", Visual Studies (22): 155-68.

Burri, R. V. (2012). "Visual Rationalities: Towards a Sociology of Images", Current Sociology 60 (1): 45-60.

Cancian, Frank (1971). Another Place San Fransisco: Scrimshaw.

Chalfen, Richard (1987). Snapshot Versions of Life. Bowling Green, OH: Bowling Green State University Popular Press.

Chalfen, Richard (2003). "Celebrating Life After Death: The Appearance of Snapshots in Japanese Pet Gravesites". Visual Studies (18):144-56.

Chaplin, Elisabeth (1994). Sociology and Visual Representation. London: Routledge

David, Emmanuel A. (2007). "Signs of Resistance: Marking Public Space Through a Renewed Cultural Activism", Visual Research Methods, ed.G. Stanczak, London: Sage, s: 225-54.

Debord, Guy. (2001). "Separation Perfected". Visual Culture. London: Sage, s. 95-98.

Değirmenci, Koray (2015). “Fotoğrafta Alan Derinliği, Belirtisellik ve Temsil İlişkisi Üzerine”, YEDİ: Sanat, Tasarım ve Bilim Dergisi (13): 1-10. 
Deleuze, Gilles ve Felix Guattari (1996). "Algılam, Duyulam ve Kavram”. Felsefe Nedir? çev. Turhan Ilgaz, İstanbul: YKY, ss. 146-177.

Doğan, Hülya, (2013). "Antropolojinin Görseli Yeniden ve Yeniden Keşfi: Görsel Antropoloji”, İletişim Kuram ve Araştırma Dergisi - Gazi Üniversitesi İletişim Fakültesi Süreli Elektronik Dergi (36): 74-85.

Edge, Sarah (1998). "The Power to Fix the Gaze: Gender and Class in Victorian Photographs of Pit-Brown Women", Visual Sociology (13): 37-56.

Goffman, Erving (1979). Gender Advertisements. London: Macmillan.

Gold, Steven J. (2007). "Using Photography in Studies of Immigrant Communities: Reflecting Across Projects and Populations". Visual Research Methods, ed. G. Stanczak, London: Sage, s: 141-66.

Grady, John (2001). “Becoming a Visual Sociologist”, Sociological Imagination 38(1): 83-119.

Grady, John (2007). "Advertising Images as Social Indicators: Depictions of Blacks in LIFE Magazine, 1936-2000”, Visual Studies (22): 211-39.

Grimshaw, Alan ve A. Ravetz, eds. (2004). Visualizing Anthropology: Experimenting With Image-Based Ethnography. Bristol, TN: Intellect Books.

Hamilton, Peter, ed. (2007). Visual Research Methods. London: Sage.

Hansberry, Lorraine (1964). The Movement: Documentary of a Struggle for Equality. New York: Simon and Schuster.

Harper, Douglas (1988). "Visual sociology: Expanding sociological vision”, American Sociologist (19): 54-70.

Harper, Douglas (2002). "Talking About Pictures: A Case for Photo Elicitation”, Visual Studies (17):13-26.

Larson, Heidi (1999). "Voices of Pacific Youth: Video Research as a Tool for Youth Expression”, Visual Sociology (14): 163-72.

Lynd, Robert S. ve Helen M. Lynd (1929). Middletown: A Study in Contemporary American Culture. New York: Harcourt, Brace, and Company.

Lynd, Robert S. ve Helen M. Lynd (1937). Middletown in Transition: A Study in Cultural Conflicts. New York: Harcourt, Brace, and Company.

MacDougall, David (1975). "Beyond Observational Cinema". Principles of Visual Anthropology, ed. Paul Hockings, The Hague/Paris: Mouton de Gruyter, s: 109-24.
Margolis, Eric (1994). "Images in Struggle: Photographs of Colorado Coal Camps”, Visual Sociology (9):4-26.

Margolis, Eric (2004). "Looking at Discipline, Looking at Labour: Photographic Representations of Indian Boarding Schools", Visual Studies (19): 72-96.

Mewhall, Nancy (1975). P H. Emerson. MiUleriown.NY: Aperture.

Musello, Christopher (1979). “Family Photography”. Images of Information, ed. J. Wagner. Beverly Hills, CA: Sage, s: 10118.

Oral, Merter (2006). “Fotoğraf ve Toplumsal Değiş̧me”, Toplum Bilim (19): 17-23

Page, Edwin R. (2001). "Social Change at Bike Week", Visual Sociology (16): 7-35.

Papademas, Diana (ed.) (1993). Visual Sociology and Using Film/ Video in Sociology Courses ( $4^{\text {th }}$ Edition). Washington, DC: American Sociological Association.

Pauwels, Luc (1993). “The Visual Essay: Affinities and Divergences Between the Social Scientific and the Social Documentary Modes", Visual Anthropology (6):199-210.

Pauwels, Luc (1996). “Representing Moving Cultures: Expression, Multivocality and Reflexivity in Anthropological and Sociological Filmmaking". Visual Cultures of Science: Rethinking Representational Practices in Knowledge Building and Science Communication, ed. L. Pauwels, Hanover and London: Dartmouth College Press-University Press of New England, s: 120-52.

Pauwels, Luc (2010). "Visual sociology reframed: An analytical synthesis and discussion of visual methods in social and cultural research", Sociological Methods and Research 38(4): 545-581.

Prosser, Jon (2007). "Visual Methods and the Visual Culture of Schools", Visual Studies (22):13-30.

Rascaroli, Laura (2008). "The Essay Film: Problems, Definitions, Textual Commitments", Framework: The Journal of Cinema and Media 49(2): 24-47.

Riis, Jacob (1981 [1892]). How the Other Half Lives. New York: Darnby Books.

Rosaldo, Renato (1989). "Grief and the Headhunter's Rage”. Culture and Truth, s: 1-21.

Rouch, Jean. (2003). “The Camera and Man”, Principles of Visual Anthropology, Paul

Hockings (ed.), Berlin: Mouten de Gruyter.

Ruby, Jay (2000). Picturing Culture: Explorations of Film and Anthropology. Chicago: University of Chicago Press. 
Simmel, George (2009) “Metropol ve Zihinsel Hayat” içinde George Simmel Bireysellik ve Kültür, çev. Tuncay Birkan, İstanbul: Metis Yayınları, s: 317-329.

Simmel, George (2009). "Duyuların Sosyolojisi”. George Simmel Bireysellik ve Kültür, çev: Tuncay Birkan, İstanbul: Metis Yayınları. s: 219-231.

Sontag, Susan (1993) Fotoğraf Üzerine, çev. Reha Akçakaya, İstanbul: Altıkırkbeş Yayınları.

Stasz, Clarice (1979). "The Early History of Visual Sociology”. Images of Information, ed. Jon Wagner, Beverly Hills: Sage Press, s: 119-137.

Strand, Paul (1971) Retrospective Monograph. Aperture.

Suchar, Charles (1992). "Icons and Images of Gentrification: The Changed Material Culture of an Urban Community". Gentrification and Urban Change: Research in Urban Sociology, ed. R. Hutchinson, Greenwich, CT: JAI, s: 33-55.

Vertov, Dziga (2007). Sine-Göz. İstanbul: Agora Yayınları.

Wagner, Jon (1999). "Beyond the Body in a Box. Visualizing Contexts of Children's

Action”, Visual Sociology (14):143-60.

Wright, Terrence (2001). "Reflections on 'The Looking Glass War': Photography, Espionage and the Cold War”, Visual Sociology (16): 75-88.

\section{İnternet Kaynakları}

Antmen Ahu (2007). “Bourdieu, Cezayir ve görsel sosyoloji”, http://www.radikal.com.tr/haber.php?haberno $=222746$ (28.04.2015)

Baker, Ulus (2002b). "Video Üstüne”

http://www.korotonomedya.net/kor/index. php?id=21,197,0,0,1,0 (28.04.2015) 